\title{
VALUE OF LANGUAGE BACKGROUND ON IDEA GENERATION SESSIONS IN FIRST-YEAR ENGINEERING DESIGN TEAMS
}

\author{
Penny Kinnear $^{a *}$, Patricia Sheridan ${ }^{b \Delta}$, Doug Reeve ${ }^{b}$, and Greg Evans ${ }^{b}$ \\ ${ }^{a}$ Engineering Communication Program, ${ }^{b}$ Institute for Leadership Education in Engineering and Dept. of Chemical \\ Engineering and Applied Chemistry \\ Faculty of Applied Science and Engineering, University of Toronto, ON, Canada; \\ *penny.kinnear@utoronto.ca, ${ }^{\Delta}$ patricia.sheridan@utoronto.ca
}

\begin{abstract}
An ongoing debate around classroom organization decisions, particularly with regard to team formation, involves the value associated with teammember diversity. Diversity can be defined, for example, in terms of discipline, marks, race, gender, language, age, experience, or goals. For the researchers in this case, this debate around the impact of diversity motivated further analysis of just what, if any, impact linguistic diversity had on teams in first-year engineering design courses. This is of particular concern given the dramatic increase in the percentage of multilingual students that make up current student bodies across Canada. Our analysis indicates that the effect of having non-native speakers of English (NNSE) on a team is not a de facto detriment to idea generation and discussions within the team. Thus, this paper reports on the effects of multilingualism on team dynamics and idea generation. The authors present here a subset of the data from of a much larger study on effective teamwork behaviours, that highlights two multilingual dominant teams from the larger study. The analysis examines how multilingualism and values associated with it contributed to and developed an integrated understanding of both the problem being addressed and potential solutions to that problem.
\end{abstract}

Keywords: teamwork, language diversity, communication, engineering design

\section{INTRODUCTION}

An ongoing debate around classroom organization decisions, particularly with regard to team formation, involves the value associated with team-member diversity. Diversity can be defined, for example, in terms of discipline, marks, race, gender, language, age, experience, or goals. For the researchers in this case, this debate around the impact of diversity motivated further analysis of just what, if any, impact linguistic diversity had on teams in first-year engineering design courses. This is of particular concern given the dramatic increase in the percentage of multilingual students that make up current student bodies across Canada - currently $30 \%$ of the incoming classes at the researchers' institution is classified as multilingual (e.g. those students have submitted a standardized language proficiency measure such as TOEFL or IELTS). Our analysis indicates that the effect of having non-native speakers of English (NNSE) on a team is not a de facto detriment to idea generation and discussions within the team. Thus, this paper reports on the effects of multilingualism on team dynamics and idea generation. The authors present here a subset of the data from of a much larger study on effective teamwork behaviours, that highlights two multilingual dominant teams from the larger study. The analysis examines how multilingualism and values associated with it contributed to and developed an integrated understanding of both the problem being addressed and potential solutions to that problem.

Linguistic diversity as an asset (and a common characteristic of a majority of students around the world) has gained recognition and prominence in the research and pedagogical agendas of linguists and applied linguists over the past ten years. [1] Relevant to the context examined in this paper are the linguistic and communicative resources and competencies multilingual students bring to their teams. Because communication is critical to both team dynamics and to the production of the course deliverables, both documents and designs, the resources the multilingual students bring to their teams can facilitate their ability to contribute to a discussion, produce spaces for others to contribute and disagree or challenge others' ideas. Multilinguals have had communication experiences in multiple languages and cultural contexts. They have also often learned in different schooling institutions and cultures. These experiences, knowledges and languages can be resources they can call on to facilitate their own and others' interactions. [2], [3], [4]

Team diversity has been of interest in the engineering community to determine how to form teams that have a lower probability of dysfunction. Criteria that have been investigated include personality traits, experience, gender identity, and cultural background. Analysis has traditionally stated that diverse teams bring more perspectives to the table, resulting in more creative or diverse solutions to the problems the teams are addressing [5]. However, a large part of the literature has focused on the negative effects of diversity and how to mitigate them rather than how to exploit the positive effects to build more 
effective teams [6]. In terms of cultural diversity (a proxy for linguistic diversity) research has stated that teams with greater cultural diversity are more challenging to form effectively as social identity theory states that students may feel threatened by the 'others' on their team [7]. In engineering, student complaints with respect to linguistic diversity have focused around not being able to have fast paced discussions within their teams, or how 'slow' team members who are non-native speakers of English detract from the team's effectiveness. Our research focuses instead on the positive aspects of teams of multilingual students, and demonstrates how some student teams leveraged these differences effectively.

The researchers followed seven teams in depth through their four-month design team experiences. None of the seven teams were monolingual, but each of the seven teams used English as the lingua franca during the recorded team meetings. This paper analyzes data from two of those teams. Team 1 comprised four other-language dominant NNSE and two English dominant students. Team 2 comprised three NNSE, all of whom had experienced their initial education in their native language or a second language and subsequently added English as a second or third language. Through a combination of meeting recordings, self- and peer-assessments, and stimulated recall interviews (SRI), the researchers were able to develop an understanding of the role of linguistic diversity on the way the three teams engaged in idea generation and the influence of their team's language diversity on their team processes of developing an understanding of both their design problem and potential solutions to that problem. We compare the ways in which the team members engaged in seeking and including the input of team members, being able to openly express ideas and opinions, and attentive listening. The ways in which the teams demonstrated attempts to understand each other's ideas and clarify those ideas were distinctly different between the teams. However, both teams co-developed their understanding of their design problem and their ideas through a conscious process of seeking to be "on the same page" about both.

\section{METHODOLOGY AND METHODS}

\subsection{Theoretical Grounding}

It is important to make explicit the theoretical grounding and perspective of the researchers. They have chosen to use a sociocultural perspective, grounded in the work of L. S. Vygotsky [8] and most recently, W-M. Roth and colleagues. [9], [10], [11] This is critical for two reasons: the unit of analysis used and the relationship of cause and effect. The unit of analysis is an entire interaction, not single utterances of individuals. This is necessitated when an interaction is understood as dialogic, where all interlocutors' contributions are seen to both form and be formed by the contributions to others. The conversation is a joint construction of meaning(s), with varying degrees of shared understandings. This understanding of the interdependence of individual utterances as well as the backgrounds and previous experiences that the individuals bring to the interactions has important implications for identifying specific cause and effect relationships. Working with this unit of analysis precludes a direct cause and effect relationship among variables (e.g. cultural and linguistic diversity results in more cognitive flexibility) but rather identifies affordances that may or may not be acted on in positive ways. While this particular perspective may be frustrating to those looking for explicit practices to implement in order to achieve certain pedagogical goals, it does encourage/enable an awareness of the many affordances and the ability to focus student (and instructor) attention to those affordances as potential tools.

In terms of teamwork, we looked at behaviours that were and were not effectively leveraged from the teameffectiveness inventory (TEI) developed by Sheridan et. al. [12] In terms of facilitating effective interactions three behaviours - listening and paying attention, seeking and including the input of others, and openly expressing ideas and opinions - were investigated. Seeing these behaviours in all team members would imply that all individuals on the team had an equitable and valued voice, that all were invited to share their thoughts and were provided spaces with which to do so. As a result, demonstration of these behaviours in team interactions would afford the teams a space to leverage the expertise and knowledge of all members of their teams.

\subsection{Study Design and Methods}

This study comprises a part of a larger study on how first-year engineering design teams make meaning and develop into effective teams. Student teams were invited to participate in an non-participatory observation study on their teamwork and communication. Three team meetings were video recorded at different points in the term, and students individually followed up with at the end of term in a stimulated recall interview (SRI). Students were compensated $\$ 30$ for participating in the study.

Videos were analysed through the theoretical grounding discussed above and were analysed using discourse, conversation, and behavioural analysis. Student speech, gaze, gesture, and interaction with learning supports (whiteboard, course documents) and their design concepts were analysed to identify: i) which behaviours from the TEI students were demonstrating, ii) how their speech and gaze affected the reception of those behaviours, and iii) how students leveraged their design concepts and learning supports to create a shared understanding of both their design problem and concept to address it.

All names used in this paper are pseudonyms. 


\subsection{Context}

This paper discusses two teams' interactions in the idea generation stage of their design processes and in the second video-recording of their team. Both teams worked in a quiet room that had a whiteboard present and a large oval table around which to work. Students at times were clustered around the whiteboard, seated around the table with notes of previous ideas generated, or a combination of both.

Team 1, was made up of 6 members who neither knew one another nor had worked together. Team 1 had two English dominant team members, one of whom was actively studying a second language, and four NNSE, all of whom had the majority of their formal education in a language other than English, had studied English as a foreign language and two of whom indicated in their conversations that they had studied in English for one or two years. There was a range of proficiency and perceived proficiency among them.

Team 2 had only 3 members who knew one another previous to working together. Team 2 was comprised entirely of NNSE who maintained the use of English throughout the recorded sessions. Although they all exhibited less than accurate or precise use of the English language, they were consistently able to establish shared meanings with one another.

As there were no monolingual teams in the larger study, no comparisons between monolingual and multilingual teams were possible.

\section{TEAM INTERACTIONS}

Our analysis of these two teams showed that neither the quality of participation nor the kinds of ideas generated differed in correlation with language diversity. Although both teams followed different interactional patterns, both were inclusive and supportive in tenor. We also found that Team 2, an exclusively NNSE team, generated a range of potential solutions from highly feasible and predictable to fanciful and silly, just as Team 1 had. Teams 1 and 2 used language and vocabulary differences to further understand the problem as well as clarify and build ideas. Both teams invited others to contribute and share both ideas and feedback on the ideas through gaze, gesture, and verbal cues. No individual in either team was shut out from asking for or offering a clarification of an idea, and was invited to continue asking questions/challenging until the idea was understood and accepted by all. Team members were attentive to the speaker and the ideas during presentation, and were not distracted or playing on their phones at any time during the discussions.

\subsection{Team 1}

Team 1 followed a more structured sharing of their ideas, working their way around the table but allowing people to pass if they did not have any idea to share at their turn. One team member recorded ideas on the board once the team had collectively developed a shared understanding of the idea put forward by an individual. While the interlocutors' focus was on the words and their meanings in that context, the focus on establishing shared understanding of the meanings of words contributed to understandings of the idea that was being developed. The process embodied by this team demonstrated a strong positive value assigned to questioning as a path to understanding, the positive value of perspectives different from your own and the idea that they could and did each learn from one another.

During Team 1's idea generation we found examples of how individual team members would start an idea and pause, unsure how to complete the idea. Another team member would then pick up the germ of the idea and suggest a clarification or expansion of that idea. Both confirmation of the direction of the development or clarification was observed from the originator of the idea or a third team member who would continue and add more to the idea with non-verbal assent from the first two. The idea would only be recorded on the whiteboard when the entire team granted permission or agreed on a common understanding of the idea either verbally through a lack of disagreement, or non-verbal gaze and gesture (nodding). This collaboration to build an idea was well illustrated at the beginning of their brainstorming session when Meaghan started to describe her idea but couldn't produce a precise description - she couldn't find the words to describe what she was thinking. Analyn jumped in to add some clarification and expansion of Meaghan's initial illformed description. As $\mathrm{Wu}$ began to write the idea on the whiteboard, he turned and asked "what does that mean?". Yin immediately provided an explanation, that Meaghan overlapped and added to followed by agreement from Analyn and finally $\mathrm{Wu}$ writing it on the whiteboard. Team 1 focused their clarifications on the ideas being expressed and ensuring the whole team shared that understanding.

Team members expressed in their SRIs the value of spending meeting time on such clarification and confirmation moves, even if it slowed down the process of generating ideas. They valued those moves as a way of ensuring the quality of their work. One team member explicitly stated that he found the statement of different understandings was useful in generating ideas. The team as a whole practiced an open and supportive communication context where questions and critiques from teams' members were elicited, encouraged and not judged but, as another team member stated, helped out to negotiate ideas. 


\subsection{Team 2}

Team 2 followed an individual-to-group structure to their brainstorming, with the group section being substantially less structured than Team 1's. One team member recorded all the ideas generated during the individual phase on the board, and then the team worked their way down the list. While each item was discussed, there was no structure to the contribution patterns in terms of who spoke (like Team 1), instead the team followed where the idea went continually following their collective trains of thought. Team members interrogated one another's ideas, critiqued them (often loudly), and asked challenging questions of the idea to any team member not just the person who generated it.

Differing from Team 1, their clarifications and confirmation questions focused on word meanings, syntactical usages and cultural interpretations of physical signs. The discussion prompted by the team's evaluation of one of their ideas against a list of design criteria they generated illustrates their interactive pattern and the role of word meanings and cultural sign interpretation. The first idea on their list was "bus". It was challenged on the first of their criteria, "cost". It was also challenged on what they had learned about the community where this design would be used--people didn't drive, they walked. To prove that even though the community walked, roads were available, one team member called up Google Street view to show there was a road big enough for a bus. The team studied the street view images and concluded that because there were no lines on the road, it wasn't big enough. However, the team member persisted and zoomed out and interpreted the map lines indicated a "major" road and a "major" road could handle a bus. The other two pushed back against the interpretation of a major road pointing out the lack of lane lines that would be associated with a major road. This segued into a new idea, a "train" like those used in amusement parks. An objection was raised about the cost of providing rails-going back to their list of criteria, followed by a clarification that not all "trains" required rails that some trains had normal "wheels". The discussion about rails, roads, lanes, and space eventually prompted the suggestion of a "Harry Potter" train, a laugh and a move to evaluate the next idea on their list. The team had to clarify what they understood by road, how they interpreted the presence or lack of lane markings, and multiple meanings of "wheel". They did so by challenging, often in fragmented sentences and with imprecise vocabulary. However, the clarification and evaluation of potential solutions informed and developed their understanding of their design problem.

The team valued critique and practiced it regularly. The team members found critique of their performances, ideas, and products something familiar from their own educational backgrounds. They stated in their SRIs that critique was not taken as something personal, but as a tool to improve and learn.

\subsection{Inferences from our Teams}

The ability to recognize and value different skills and pools of knowledge can be interpreted as a result of the multilingual students broad learning and living experiences. Specifically, we can see this in the way that Team 1 articulated their respect for Jing's contributions. Although he was not a vociferous contributor, his comments were treated with respect and valued when he made them. It was also seen in the way that they respected Wu's pointed questions about an idea or a decision. Team 2 also showed this willingness to value different skills and perspectives. Amy acknowledged Case's superior ability to find research relevant and interesting to their project. Grant acknowledged that Amy's annoying habit of focusing on feasibility and practicality which conflicted with his own interest in pursuing something original and different, was a necessary contribution to their ability to move forward with their design.

The key piece that made these discussions effective was that the teams had established a process by which to seek and include input from all team members and to listen and pay attention to each other. Though each team demonstrated these processes differently, it created a sense of value for the team members in knowing that they would be heard and could try out different ideas that the team could figure out collectively. Meaghan said this best in her SRI:

"I'd say ya silence was pretty much erased near the end where like pretty much everyone was willing to throw out ideas or like talk about everything. Here, in the beginning, ya it took a little bit more prodding maybe. Ya in the end we ended up having like most team members just randomly discuss much of things. And pretty well. Again I think it comes back to the familiarity, like we got used to each other were willing to just continue a discussion like throw out random ideas even if they don't fully make sense. If you are more willing to just go "oh yeah and what if we did you know this with like a tree or whatever" and just throw out something random and see how people react"

While this was described best by Meaghan, the sentiment was captured in both teams. In SRIs, students described a sense of being valuable, of being free to contribute however/whatever you were thinking, and that even if your idea wasn't perfect, that wasn't your sole responsibility - the team would get it there collectively.

These interaction patterns may not have stemmed directly from the multilingual composition of the teams, however, these patterns did afford greater contribution and 
freedom to express imperfect ideas from those who were NNSE.

Multilinguals were not a defacto detriment to a productive team environment. Their ability to explore ideas in depth was not limited by any language imprecision and inaccuracy that we had historically heard were issues. We saw this in the idea building with Team 1 when others articulated an idea from one individual's intention. We saw this also in Team 2 as they explored ideas that would not have made sense to their stakeholders, but through that free exploration of impractical ideas allowed for a better understanding of their problem. The way in which students were able to explore their design space and their solution space was not impeded by having a lower English language accuracy or fluency. Instead, we saw that students questioned ideas and contexts more, and as a result were better able to explore their design space more effectively. We also saw less individual attachment to ideas in both teams, as students co-constructed the ideas by building on each other's contributions.

\section{CONCLUSIONS}

We have chosen to focus on the two teams who positively leveraged the affordances of their cultural and linguistic diversity (either explicitly or implicitly) to facilitate effective idea generation that was inclusive and developed from the expertise of all team members. Analysis from a team dynamics perspective showed that in the process of generating, clarifying, and developing the ideas Teams 1 and 2 were able to seek and include the input of others because no negative judgment was attached to the act of clarifying a word or idea. Through all team members listening and paying attention to others, team members were encouraged to openly express their ideas and opinions, and were more comfortable expressing parformed or grammatically inaccurate ideas. From the findings presented in this paper there is not sufficient evidence to claim that diversity causes a certain effect. This paper simply highlights that students who do leverage their multilingualism as an affordance can use it to make their design-team work more effective. Future work will analyse teams who made ineffective or limited use of their language diversity in an attempt to ascertain ways to increase the leveraging of these affordances.

\section{Acknowledgements}

This research was supported by the Social Sciences and Humanities Research Council of Canada and the Ontario Graduate Scholarship Program. The authors would like to thank the students who participated in the study, the course instructors who gave them access to their classes, and Gregory Bruce for his feedback on this paper.

\section{References}

[1] J. Cenoz and D. Gorter, "A holistic approach to multilingual education: Introduction," The Modern Language Journal, vol. 95, pp. 339-343, 2011.

[2] R. Franceschini, "Multilingualism and multicompetence: A conceptual view," The Modern Language Journal, vol. 95, pp. 344-355, 2011.

[3] J. Cenoz and D. Gorter, "Towards a plurilingual approach in English language teaching: Softening the boundaries between languages," TESOL Quarterly, vol. 47, pp. 591599, 2013.

[4] S. Marshall and D. Moore, "2B or not 2B plurilingual? Navigating languages literacies, and plurilingual competence in postsecondary education in Canada," TESOL Quarterly, vol. 47, pp. 472-499, 2013.

[5] S. Friis, "Including diversity in creative teamwork in design education," International Journal of Design Creativity and Innovation, vol. 3, no. 3-4, pp. 239-255, 2015.

[6] G. K. Stahl, K. Makela, L. Zander and M. L. Maznevski, "A look at the bright side of multicultural team diversity," Scandinavian Journal of Management, vol. 26, pp. 439447, 2010.

[7] S. Mohammed and L. C. Angell, "Surface- and deep-level diversity in workgroups: examining the moderating effects of team orientation and team process on relationship conflict," Journal of Organizational Behaviour, vol. 25, pp. 1015-1039, 2004.

[8] L. S. Vygotsky, The collected works of L.S. Vygotsky: Volume 1 Problems of general psychology including the volume Thinking and Speech, New York, NY: Plenum Press, 1987.

[9] W.-M. Roth, "Socio-cultural perspectives on learning science," in Encyclopedia of science education, Berlin Heidelberg, Springer-Verlag, in press.

[10] W.-M. Roth, "An integrated theory of thinking and speaking that draws on Vygotsky and Bakhtin/Volosinov," Dialogic Pedagogy, vol. 1, pp. A32A53, 2013.

[11] L. Radford and W.-M. Roth, "Intercorporeality and ethical commitment: An activity perspective on classroom interaction," Educational Studies in Mathematics, vol. 77, pp. 227-245, 2011.

[12] P. K. Sheridan, P. M. To, G. J. Evans and D. W. Reeve, "An On-line Team-effectiveness Learning System," in Proceedings of the Canadian Engineering Education Annual Conference, Canmore, AB, 2014. 